\title{
A Spectroscopic Paradox: The Interaction of Methanol with ZSM-5 at Room Temperature
}

\author{
Andrea Zachariou ${ }^{1,2}\left(\right.$ D $\cdot$ Alexander P. Hawkins ${ }^{1,2}\left(\mathbb{0} \cdot\right.$ Russell F. Howe $^{4}\left(\mathbb{D} \cdot\right.$ Nathan Barrow $^{3} \cdot$ Jonathan Bradley $^{3}$. \\ Paul Collier $^{3} \cdot$ David Lennon $^{1}$ (i) $\cdot$ Stewart F. Parker ${ }^{1,2,5}$ (i)
}

Accepted: 4 June 2021 / Published online: 29 July 2021

(C) The Author(s) 2021

\begin{abstract}
The adsorption of methanol in HZSM-5 at low temperatures has long been regarded as an associative process involving hydrogen bonding to the acidic zeolite hydroxyl groups. Recent studies employing inelastic neutron scattering spectroscopy (INS) have reported that complete dissociation to methoxylate the zeolite occurs at $298 \mathrm{~K}$, and infrared evidence for a partial dissociation at $298 \mathrm{~K}$ has also been described. Here we investigate the apparent contradictions between different techniques, using a combination of INS, infrared spectroscopy and solid-state NMR spectroscopy, including isotopic substitution experiments. Different possible explanations are proposed and considered; we conclude that at room temperature methanol is very largely associatively adsorbed, although the presence of some small extent $(>1 \%)$ of methoxylation cannot be ruled out.
\end{abstract}

Keywords HZSM-5 $\cdot$ Inelastic neutron scattering (INS) $\cdot$ Room temperature methoxylation $\cdot$ Hydrogen bonded methanol DRIFTS · NMR

\section{Introduction}

The interaction between methanol and acidic zeolite catalysts is important because of its relevance to Methanolto-Hydrocarbons (MTH) technology. In MTH, methanol derived from coal or natural gas is converted into more valuable industrially relevant hydrocarbons, including light olefins and methylated aromatics. HZSM-5 zeolite was one of the first catalysts used for this reaction $[1,2]$. The mechanisms of hydrocarbon formation from methanol have been widely studied [3-7], and it is generally accepted that

Stewart F. Parker

stewart.parker@stfc.ac.uk

1 School of Chemistry, University of Glasgow, Joseph Black Building, Glasgow G12 8QQ, UK

2 UK Catalysis Hub, Research Complex at Harwell, STFC Rutherford Appleton Laboratory, Chilton OX11 0FA, Oxon, UK

3 Johnson Matthey Technology Centre, Blounts Court, Sonning Common, Reading RG4 9NH, UK

4 Department of Chemistry, University of Aberdeen, Aberdeen AB24 3UE, UK

5 ISIS Facility, STFC Rutherford Appleton Laboratory, Chilton OX11 0QX, Oxon, UK the first step is the reaction of methanol with the zeolite's Brønsted sites to generate methoxy species, as shown in Scheme 1 [8-10].

For example, Forester and Howe [10] carried out an in-situ FTIR study of methanol in HZSM-5. At room temperature, the spectra showed only bands characteristic of hydrogen bonded species. Pulsing methanol under flowing helium at temperatures above $373 \mathrm{~K}$ showed methoxylation of the acid sites, revealed by loss of the zeolite $\nu(\mathrm{OH})$ band and appearance of new bands in the $\mathrm{CH}$ stretching and bending regions. The room temperature interaction of methanol with HZSM-5 was subsequently studied in more detail by Zecchina et al. [11]. The infrared spectra varied with the methanol loading. At low loadings $(<1$ molecule per acid site) hydrogen bonding of individual methanol molecules to zeolite $\mathrm{OH}$ groups was observed, manifested in the appearance of an $\mathrm{ABC}$ triplet due to interception of the broad $\mathrm{OH}$ stretching mode of the hydrogen bonded zeolite $\mathrm{OH}$ groups by Fermi resonance with overtones of $\delta(\mathrm{OH})$ and $\gamma(\mathrm{OH})$ modes [11-13]. At higher coverages, formation of protonated clusters of methanol through complete proton transfer from the $\mathrm{OH}$ groups was reported.

In contrast, a more recent study of methanol interaction on both ZSM-5 and HY using inelastic neutron scattering (INS) spectroscopy and quasielastic neutron scattering 
Scheme 1 Schematic of methoxylation reaction occurring when methanol is introduced into an acidic zeolite catalyst

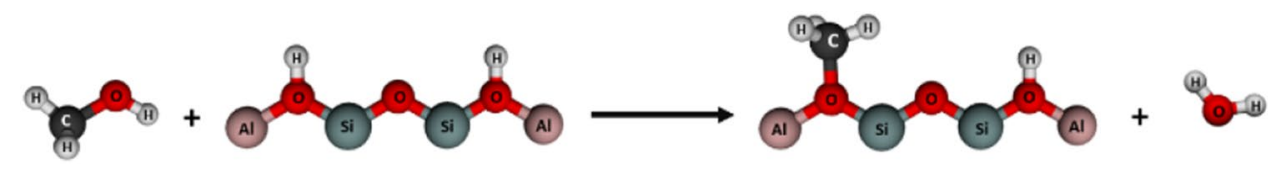

(QENS) reported complete methanol dissociation to methoxy species at room temperature on HZSM-5 [14]. Methanol was dosed on the dehydrated zeolite at room temperature under He flow. The QENS spectra of the dosed ZSM-5 showed no broadening of the elastic peak suggesting no movement in the zeolite framework, which was contrasted with a dosed HY sample where significant broadening was observed [14]. The INS spectra of the dosed ZSM-5 showed no deformation or stretching modes of zeolite or methanol $\mathrm{OH}$ groups, whereas in HY both stretching and deformation modes of $\mathrm{OH}$ groups were detected, consistent with hydrogen bonding of methanol. Similar QENS evidence for lack of mobility at room temperature on the QENS time scale was later reported for methanol in both a fresh HZSM-5 catalyst and one used in an MTH reactor for three days at $623 \mathrm{~K}$ [15]. Very recently a more detailed QENS study has looked at the behaviour of methanol in HZSM-5 as a function of temperature and the aluminium content of the zeolite [16]. According to this study the fraction of immobile methanol depends on both temperature and the number of acid sites in the zeolite.

A DRIFTS study by Matam et al. has suggested that it is possible to see formation of methoxy groups from methanol in HZSM-5 at room temperature by infrared spectroscopy [17], although the methoxy bands are difficult to distinguish due to the intense ABC structure of the hydrogen bonded methanol. The same group recently showed by a combination of DRIFTS and computational modelling that room temperature methoxylation is methanol loading dependent, finding that methoxylation at room temperature does not occur at loadings of less than one mole of methanol per acid site [18].

In the present study we have attempted to rationalise the apparently contradictory results obtained from the different forms of spectroscopy by applying a combination of techniques (INS, DRIFTS and solid state NMR (ssNMR)) to look at methanol in the same HZSM-5 zeolite.

\section{Experimental}

The HZSM-5 zeolite (Si:Al 30) was provided in powder form by Johnson Matthey and its characterisation can be found elsewhere [19]. Prior to use, the zeolite was calcined at $773 \mathrm{~K}$ for $12 \mathrm{~h}$ under static air. Prior to methanol adsorption the catalyst was dried at $623 \mathrm{~K}$ under flowing He $\left(100 \mathrm{ml} \mathrm{min}^{-1}\right)$. The INS experiments used the TOSCA
[20] and MAPS [21] spectrometers that are located at the ISIS Pulsed Neutron and Muon Source (Oxfordshire, UK). The instruments are complementary: TOSCA provides good resolution spectra over the $0-2000 \mathrm{~cm}^{-1}$ range, while MAPS provides access to the $\mathrm{C}-\mathrm{H}$ and $\mathrm{O}-\mathrm{H}$ stretching regions (2000-4000 $\mathrm{cm}^{-1}$ ). The MAPS spectra were collected using the A-chopper package with a fixed incident energy of $650 \mathrm{meV}(600 \mathrm{~Hz})$ and $250 \mathrm{meV}(400 \mathrm{~Hz})$ [21]. The DRIFTS experiments used an Agilent Carey 680 FTIR spectrometer with a liquid nitrogen cooled MCT detector and a Harrick Praying Mantis DRIFTS environmental chamber accessory. 64 scans per spectrum were collected at a resolution of $4 \mathrm{~cm}^{-1}$. The ss-NMR experiments were carried out using two spectrometers: a Bruker Avance III (400 MHz) Fourier transform NMR spectrometer and a Bruker Avance Neo (600 MHz) NMR spectrometer. The ${ }^{13} \mathrm{C}-\mathrm{NMR}$ experiment used the HPDEC pulse sequence which does not rely on cross-polarisation and is therefore quantitative. The INS spectra were recorded below $20 \mathrm{~K}$, the infrared and ss-NMR spectra were recorded at room temperature. Table 1 shows a summary of all the samples that were prepared.

\subsection{Flow Dosed Methanol Experiments}

The dried ZSM-5 was transferred to a flat aluminium gas handling cell in an argon filled glovebox, to prevent exposure to moisture. For flow dosed samples, the methanol dosing used a Dreschel bottle maintained at room temperature and with $1.11 \mathrm{~min}^{-1} \mathrm{He}$ flow as the carrier gas. For the flow dosed (FD) samples both $\mathrm{CH}_{3} \mathrm{OH}$ (Sigma Aldrich, 99.8\% anhydrous) and $\mathrm{CD}_{3} \mathrm{OH}$ (Sigma Aldrich, 99.7 atom\% D) were used as well as ${ }^{13} \mathrm{CH}_{3} \mathrm{OH}$ (Sigma Aldrich, 99 atom $\%{ }^{13} \mathrm{C}$ ). All of these samples were analysed by INS. The FD- ${ }^{13} \mathrm{CH}_{3} \mathrm{OH}$ was also analysed by DRIFTS and ss-NMR using the $600 \mathrm{MHz}$ spectrometer. The FD- ${ }^{13} \mathrm{CH}_{3} \mathrm{OH}$ was dosed with a mixture of $14 \mathrm{wt} \%$ ${ }^{13} \mathrm{C}$-methanol in ${ }^{12} \mathrm{C}$-methanol. For the DRIFTS experiment, the Harrick cell dome reactor was charged with the post-reaction catalyst sample inside an argon filled glove box, before being transferred to the spectrometer. For the ss-NMR experiments, the ss-NMR rotor was packed inside the glove box and sealed in an airtight container before being transferred to the spectrometer. The aluminium flat gas handling cans used for the flow-dosed samples are compatible with use inside the INS spectrometer. 
Table 1 Detailed list of samples used

\begin{tabular}{|c|c|c|c|c|c|c|}
\hline \multirow[t]{2}{*}{ Sample Name } & \multirow{2}{*}{$\begin{array}{l}\text { Zeolite mass } \\
g\end{array}$} & \multirow{2}{*}{$\begin{array}{l}\text { Methanol volume } \\
\mathrm{ml}\end{array}$} & \multirow[t]{2}{*}{ Dosing method } & \multirow[t]{2}{*}{ Technique } & \multicolumn{2}{|l|}{ Methanol loading } \\
\hline & & & & & $\mathrm{mol}_{\mathrm{MeOH}} / \mathrm{mol}_{\mathrm{ZSM}-5}$ & $\begin{array}{l}\text { mol }_{\mathrm{MeOH}} / \\
\text { acid site }^{\mathrm{a}}\end{array}$ \\
\hline \multicolumn{7}{|l|}{ Section 3.1 .1} \\
\hline FD-MeOH & 8.52 & 0.58 & Under flow & INS & 12.15 & 4 \\
\hline Section 3.1 .2 & & & & & & \\
\hline ZSM-5 w MeOH & 0.02 & 0.006 & Under flow & DRIFTS & $42.18^{\mathrm{b}}$ & 14 \\
\hline \multicolumn{7}{|l|}{ Section 3.1 .3} \\
\hline ZSM-5 w 1.2 ul MeOH & 0.050 & 0.0012 & Injection static & ${ }^{13} \mathrm{C}$-ssNMR & 3.38 & 1 \\
\hline ZSM-5 w 6.6 ul MeOH & 0.056 & 0.0066 & Injection static & ${ }^{13} \mathrm{C}$-ssNMR & 16.53 & 5 \\
\hline \multicolumn{7}{|l|}{ Section 3.2 .1} \\
\hline $\mathrm{FD}-\mathrm{CD}_{3} \mathrm{OH}$ & 5.58 & 0.64 & Under flow & INS & 17.81 & 6 \\
\hline \multicolumn{7}{|l|}{ Section 3.2 .2} \\
\hline Injection 6,RT, Before heat & 0.02 & 0.006 & Under flow & DRIFTS & $42.18^{\mathrm{b}}$ & 14 \\
\hline Injection $6, \mathrm{RT}$, after heat & Same & +0.006 & & & $42.18^{\mathrm{b}}$ & 14 \\
\hline \multicolumn{7}{|l|}{ Section 3.2 .3} \\
\hline SM-MEOH & 11.55 & 0.99 & Static dose & INS & 15.45 & 5 \\
\hline${ }^{13} \mathrm{C}-\mathrm{MeOH}, \mathrm{ZSM}-5$ & 7.45 & 0.76 & Under flow & $\begin{array}{l}\text { INS, DRIFTS, } \\
{ }^{13} \mathrm{C} \text {-ssNMR }\end{array}$ & 17.81 & 6 \\
\hline \multicolumn{7}{|l|}{ Section 3.2 .4} \\
\hline ZSM-5 w MeOD & 7.82 & 0.69 & Under flow & INS & 15.39 & 5 \\
\hline ZSM-5 w MeOH exchanged & same & 0.68 & Under flow & INS & 15.67 & 5 \\
\hline
\end{tabular}

${ }^{\mathrm{a}}$ The moles of methanol per acid site are estimated using the assumption that there are 3 acid sites per mole of ZSM-5 with a Si:Al ratio of 30

${ }^{\mathrm{b}}$ The dosing details of the DRIFTS samples is calculated based on the total volume of the methanol passed through the DRIFTS cell holder, however, how much methanol is absorbed on the sample is unknown

\subsection{Exchanged Methanol Experiments}

The dried zeolite was loaded into an aluminium gas handling cell in an argon filled glovebox as above. The $\mathrm{CH}_{3} \mathrm{OD}$ (Sigma Aldrich, 99.5 atom\% D) was loaded on the zeolite in the same way as the flow dosed samples to a level of $15.3 \mathrm{~mol}_{\mathrm{CH} 3 \mathrm{OD}} / \mathrm{mol}_{\mathrm{ZSM} 5}$, as determined gravimetrically. The sample was analysed using the MAPS spectrometer. The sample was then dosed with $\mathrm{CH}_{3} \mathrm{OH}$ (Sigma Aldrich, 99.8\% anhydrous) in order to exchange the $\mathrm{OD}$ with the $\mathrm{OH}$ until saturation was reached, achieving a new loading of 15.7 $\mathrm{mol}_{\mathrm{MeOH}} / \mathrm{mol}_{\mathrm{ZSM} 5}$, and returned to the MAPS spectrometer for collection of a post-exchange spectrum.

\subsection{Static Dosed Methanol Experiments}

$1 \mathrm{ml}$ of methanol was injected onto $\sim 10 \mathrm{~g}$ of dried ZSM-5. The zeolite was then sealed in a desiccator with a methanolsaturated atmosphere at room temperature for a period of $70 \mathrm{~h}$. The sample was then transferred to an $\mathrm{Al}$ flat can and the INS spectrum collected with both TOSCA and MAPS spectrometers. For the ss-NMR static dosed experiments, ZSM-5 was dried under vacuum and dosed with ${ }^{13} \mathrm{C}$ enriched methanol via syringe injection. Two different loadings were chosen: (i) $6.6 \mu \mathrm{l}$ methanol $\left(16.5 \mathrm{~mol}_{\mathrm{MeOH}} / \mathrm{mol}_{\mathrm{ZSM}-5}\right)$, which is comparable to the loading concentration used for the INS experiments and (ii) $1.2 \mu \mathrm{l}\left(3.3 \mathrm{~mol}_{\mathrm{MeOH}} / \mathrm{mol}_{\mathrm{ZSM}-5}\right)$, which is comparable to conditions used in infrared experiments by Forester and Howe [10] ${ }^{13} \mathrm{C}$-NMR and ${ }^{1} \mathrm{H}$-NMR spectra were recorded for both samples. The $6.6 \mu \mathrm{l}$ dosed sample was left sealed for an extra $1.5 \mathrm{~h}$ before collecting another set of ${ }^{13} \mathrm{C}$-NMR and ${ }^{1} \mathrm{H}$-NMR spectra in order to observe any changes with time, then heated to $423 \mathrm{~K}$ in order to observe partial methoxylation.

\subsection{In-Situ Experiments}

DRIFTS was used for flow dosed in-situ experiments of methanol loaded ZSM-5. The ZSM-5 was dried in-situ, using liquid nitrogen boil-off as the inert gas flow in order to minimise introduced moisture and hence avoid re-hydrating the zeolite. Methanol was then introduced into the system via manual injections through a septum into the inlet gas stream at $298 \mathrm{~K}$ and scans were completed both before and after the injections were made. The ZSM-5 was heated gradually at $5 \mathrm{~K} \mathrm{~min}^{-1}$ to $473 \mathrm{~K}$ in order to induce methoxylation before being cooled back down to room temperature. A 
second set of injections were completed at room temperature on the same sample.

\section{Results and Discussion}

This paper is structured as follows: in the first section we show the INS, DRIFTS and ss-NMR results that show apparent contradictions between the techniques. In subsequent sections we investigate possible scenarios that may reconcile the contradictory results. We conclude with a summary that describes how we believe this paradox can be resolved. To ensure consistency, the same ZSM-5 zeolite was used throughout the investigation. This particular ZSM-5 catalyst has been previously used for the MTH reaction with methanol [19], dimethyl ether [22] and methyl acetate [23] as feedstocks. As seen in the Electronic Supplementary Information (ESI) at $623 \mathrm{~K}$ with methanol it behaves as a conventional ZSM-5 catalyst with the products consisting of a range of methylated hydrocarbons, Figures S1-S3. However, when the catalyst was exposed to methanol at room temperature, other than the expected uptake of methanol, no reaction products were obtained and, importantly, no water was produced at any stage during the time-on-stream.

\subsection{Evidence for and Against Methoxylation}

\subsubsection{Inelastic Neutron Experiment}

The quantity of sample required for INS experiments limits the ways in which room temperature dosing can be completed. It must be noted that the quantity of the sample depends on the INS spectrometer used. However, even for the most sensitive instrument available (VISION at SNS); the sample size cannot match the quantity required for NMR or DRIFTS experiments $(10-60 \mathrm{mg})$. Flow dosing the methanol via a Dreschel bottle is the simplest way to load the methanol onto the dried zeolite in an INS-compatible flowthrough cell (12.15 mol $\mathrm{MeOH} / \mathrm{mol}_{\mathrm{ZSM} 5}, \sim 4 \mathrm{MeOH} /$ acid site). Figure 1 shows a comparison of solid methanol reference spectra obtained by both TOSCA and MAPS, as well as the spectra of the methanol dosed on ZSM-5 with the ZSM-5 contribution subtracted (FD-MEOH). The spectra before subtraction can be found in the ESI Figures S4-S6).

The characteristic $\mathrm{OH}$-related modes of methanol are the stretch above $3200 \mathrm{~cm}^{-1}$ and the $\mathrm{OH}$ deformations at $700 \mathrm{~cm}^{-1}$ and $780 \mathrm{~cm}^{-1}$ (there is more than one mode because there are four molecules in the primitive cell of methanol [24]). In contrast, the FD-MEOH appears to have lost the $\mathrm{OH}$ functionality; neither the $\mathrm{OH}$ stretch or deformations are present. We note that the spectra are in complete agreement with those previously reported by O'Malley et al. in an INS and QENS study of methanol in a different ZSM-5
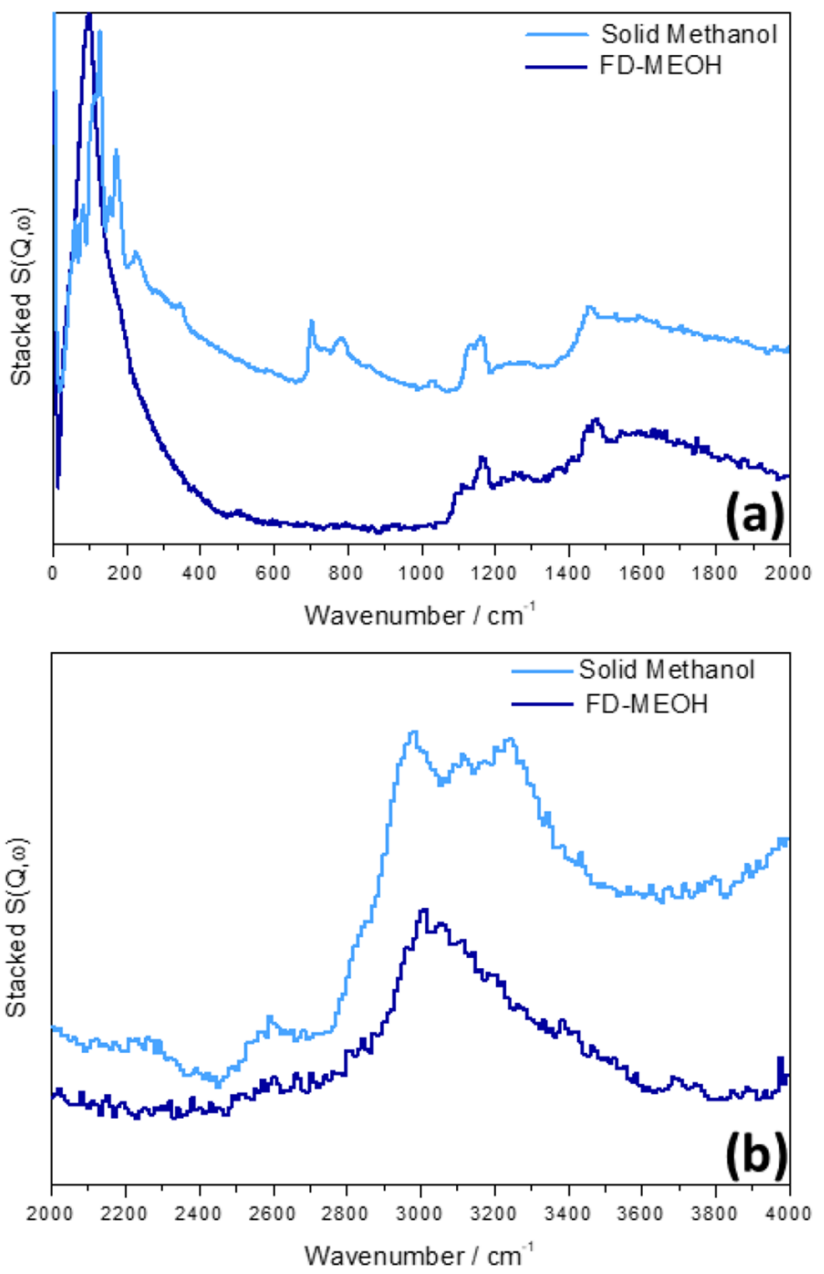

Fig. 1 Solid methanol (light blue) and flow-dosed methanol on ZSM-5 at room temperature (blue). a TOSCA spectra b MAPS spectra collected using the A-chopper at an incident energy of $5244 \mathrm{~cm}^{-1}$

zeolite [14]. The apparent loss of the $\mathrm{OH}$ functionality is indeed consistent with room temperature methoxylation.

\subsubsection{Diffuse Reflectance Infrared Fourier Transform Spectroscopy (DRIFTS)}

DRIFTS spectra were collected for the dried ZSM-5, after the injection of methanol ( 6 injections of $2 \mu$ methanol over $20 \mathrm{~min}$ ) at room temperature and during flushing with inert gas for $60 \mathrm{~min}$. Figure 2a shows the spectra of the blank ZSM-5, after methanol was injected and then flushed for 60 min under a high flow rate. The spectrum recorded on initial injection of methanol closely resembles that assigned by Zecchina et al. to a mixture of protonated methanol clusters and single methanol molecules hydrogen bonded to zeolite $\mathrm{OH}$ groups [11]. The spectra are dominated by the $\mathrm{ABC}$ triplet of hydrogen bonded methanol and a broad continuum beginning around $3300 \mathrm{~cm}^{-1}$. The difference spectra (i.e. the 
Fig. 2 a Spectra of the blank ZSM-5 (black), ZSM-5 with methanol injected under flow (blue), the sample was then flushed under $100 \mathrm{ml} \mathrm{min}^{-1}$ of $\mathrm{N}_{2}$ (grey). A final spectrum was collected after $20 \mathrm{~min}$ of flushing (green). The spectra are unsubtracted, but the intensity has been normalised using the overtone band $\left(1866 \mathrm{~cm}^{-1}\right)$ on the blank ZSM-5. The ABC triplet is highlighted (A: green, B: purple, C: pink). The difference spectra of (a) are found in the ESI in Figure S7. Detailed view of: $\mathbf{b}$ the difference spectra in the acid site region (4000-3400 $\mathrm{cm}^{-1}$ ) $\mathbf{c}$ the difference spectra in the $\mathrm{CH}$ stretch region $\left(3100-2600 \mathrm{~cm}^{-1}\right)$ and d the difference spectra of the $\mathrm{C}-\mathrm{O}$ stretch region where the $\mathrm{PQR}$ bands of gass phase methanol are found. A comparison of the difference spectrum with the spectra of liquid and gas phase methanol is shown in Figure S8.

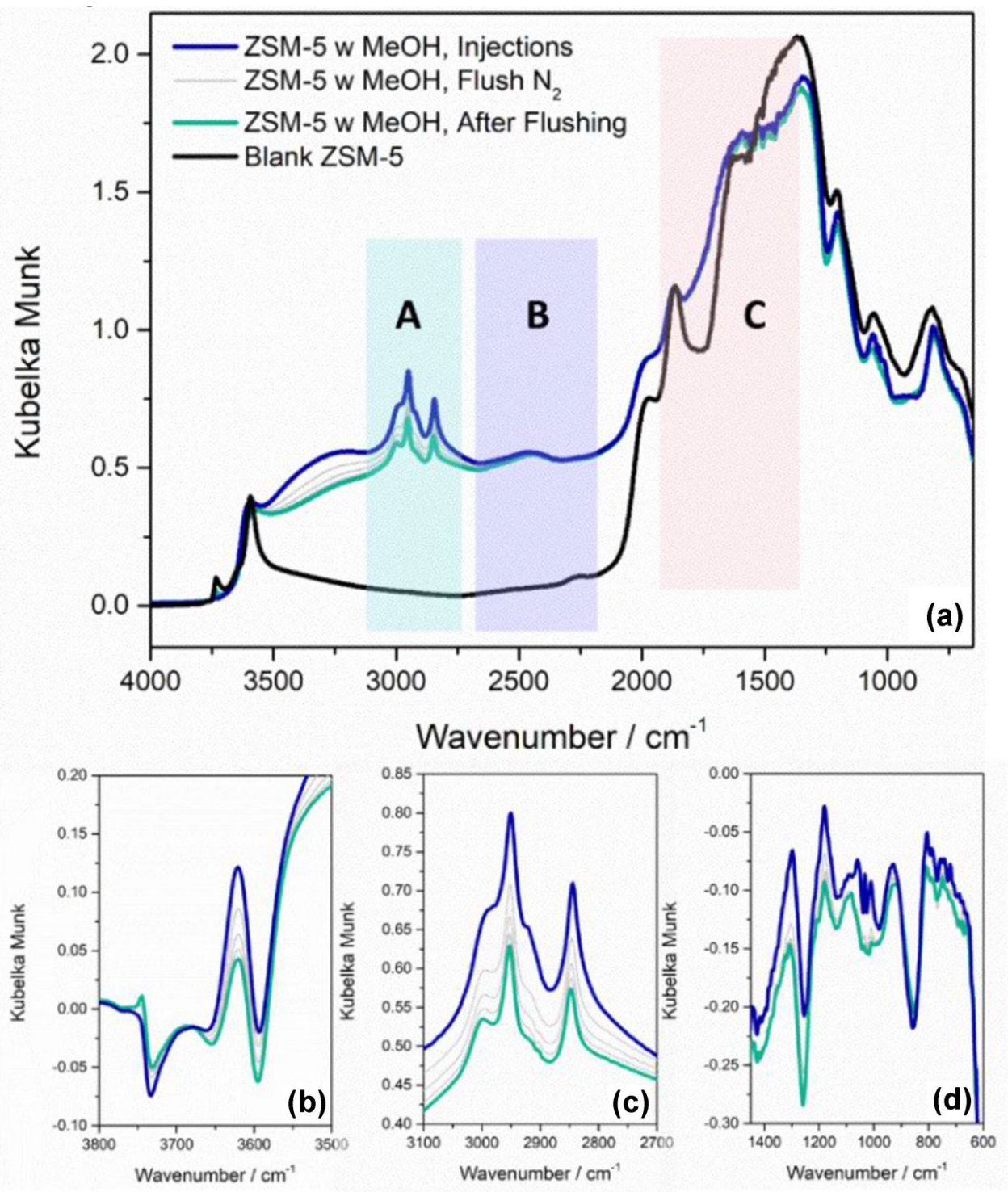

dried, bare zeolite used as the background spectrum) are shown in Fig. 2b-d. As seen in Fig. 2b, methanol interacts with all three types of zeolite $\mathrm{OH}$ groups (silanol groups, extra-framework $\mathrm{AlOH}$, and Brønsted acid sites).

On flushing at room temperature the broad $\mathrm{OH}$ band at $\sim 3300 \mathrm{~cm}^{-1}$ is removed and there is an obvious upwards shift in the highest frequency $v(\mathrm{CH})$ band (Fig. $2 \mathrm{c}$ ); the spectrum after flushing for 60 min closely resembles that assigned by Zecchina et al. [11] to single methanol molecules hydrogen bonded to zeolite $\mathrm{OH}$ groups i.e. the changes on flushing are those expected for reducing the amount of adsorbed methanol.

Difference spectra in the low frequency (1400 to $700 \mathrm{~cm}^{-1}$ ) region are difficult to interpret because of strong absorption by the zeolite lattice, perturbation of lattice modes by adsorption [25] and, in the specific case of diffuse reflectance spectra, distortions caused by dispersion effects. The very weak features appearing in the difference spectra in Fig. $2 \mathrm{~d}$ are mostly artefacts. In the initial spectrum (blue) methanol vapour is still present in the cell as seen from the PQR vibrational bands of the methanol CO stretching mode at $1000-1100 \mathrm{~cm}^{-1}$, but these disappear on flushing, as expected. Matam et al. also report loss of methanol vapour bands on flushing but in this study we did not see the new band at $1004 \mathrm{~cm}^{-1}$ assigned by Matam et al. to the CO stretching mode of surface methoxy groups [17, 18]. In the $\mathrm{CH}$ stretching region surface methoxy groups in ZSM-5 have asymmetric and symmetric stretching modes at 2980 and $2868 \mathrm{~cm}^{-1}$ respectively [10], but these bands could not be distinguished in the spectra measured here from those of hydrogen bonded methanol. 


\subsubsection{Solid State NMR}

The ss-NMR experiments were carried out via static dosing of ${ }^{13} \mathrm{C}$-methanol onto dried ZSM-5. Two loadings were used: the first $(1.2 \mu \mathrm{l}$ methanol) is comparable to that of previous studies in the literature [26] of about $3.3 \mathrm{~mol}_{\mathrm{MEOH}} /$ $\mathrm{mol}_{\text {ZSM-5 } 5}$; the second ( $6.6 \mu \mathrm{l}$ methanol) is comparable to the INS dosing experiments, $16.5 \mathrm{~mol}_{\mathrm{MEOH}} / \mathrm{mol}_{\mathrm{ZSM}-5}$. As seen in Fig. 3, the spectra for the room temperature loaded samples (black lines) at both methanol loadings showed a single Lorentzian line at $51.2 \mathrm{ppm}$, with no contribution from any other species present. This is attributed to hydrogen-bonded methanol $[7,26]$. Figure 3 a shows the NMR spectrum of the INS-comparable loaded ZSM-5 at room temperature and after heating to $423 \mathrm{~K}$. After heating the ss-NMR spectra changes significantly.

Two signals are present: the major signal at $60.2 \mathrm{ppm}$ is assigned to methoxy groups and/or dimethylether [7, 26],

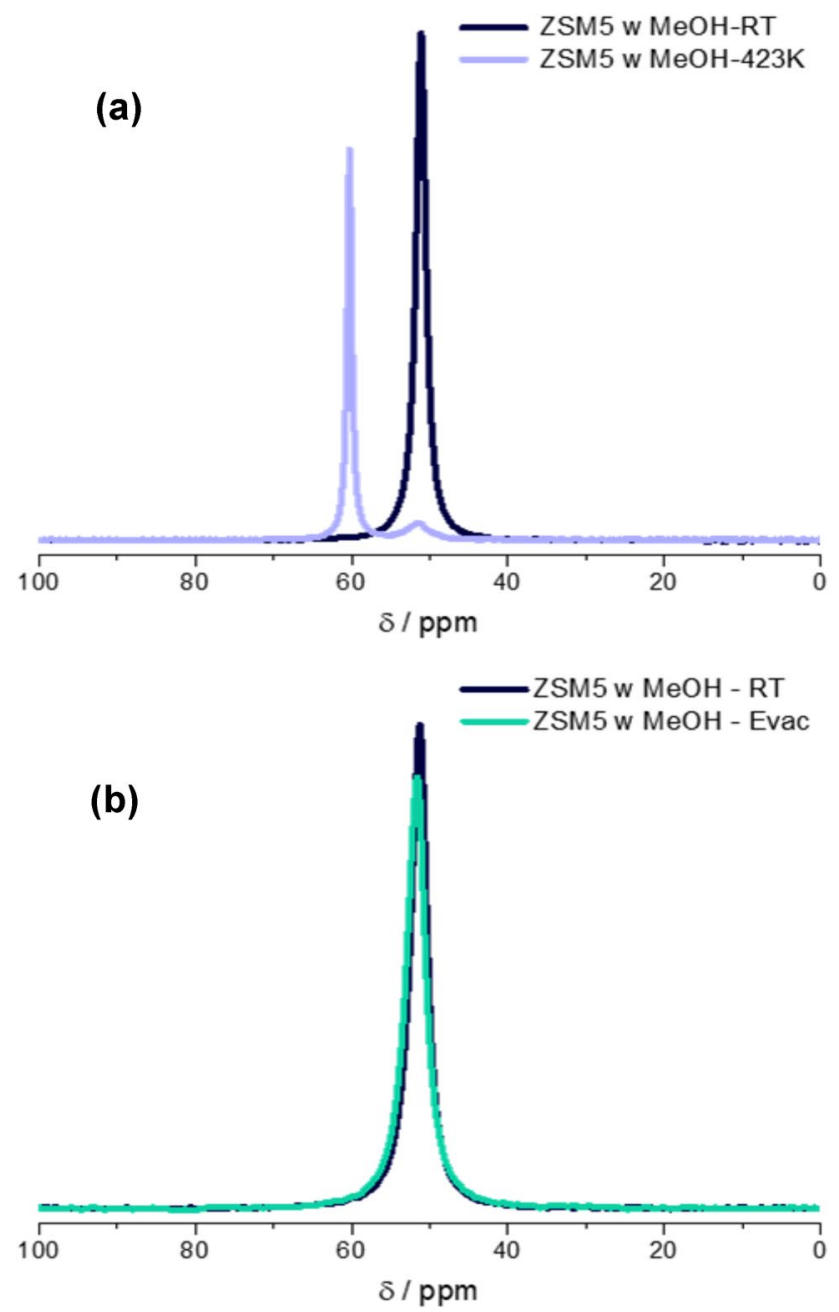

Fig. 3 ssNMR spectra a methanol dosing comparable to INS, and then heated at $423 \mathrm{~K} \mathrm{~b}$ methanol dosing comparable to Ref [9], and then evacuated to $0.3 \mathrm{mbar}$ and the smaller signal at $51.2 \mathrm{ppm}$ indicates some residual hydrogen bonded methanol in the zeolite. Figure $3 \mathrm{~b}$ shows the methanol loaded ZSM5 at room temperature as well as the spectra of the sample after it has been evacuated to 0.3 mbar. Evacuating the sample did not cause a significant change in the spectra suggesting that the methanol is strongly adsorbed on the zeolite surface. Again, no signal was observed at $60 \mathrm{ppm}$ which suggests that no methoxylation of the zeolite has occurred. Using an HPDEC pulse sequence, ${ }^{13} \mathrm{C}$ ss-NMR is quantitative, so Fig. 3 enables determination of an upper limit for the amount of methoxylation that could take place and be unseen by ss-NMR. This is determined by the signal-to-noise ratio, which for the signal at 51.2 ppm in Fig. 3a is at least 100. This means that no more than $1 \%$ of the methyl groups could be present as methoxy groups in the sample before heating. We note that these results are in agreement with previous work [7, 26].

In summary, all of the spectra presented here (INS, ssNMR and DRIFTS) are compatible with previous work in the literature. However, they present different aspects: (i) INS appears to indicate complete methoxylation with no hydrogen-bonded methanol present; (ii) ss-NMR shows only hydrogen-bonded methanol at room temperature, methoxylation only occurs on heating; while (iii) DRIFTS shows hydrogen-bonded methanol with, at most, traces of methoxy groups. In the following section we consider four scenarios that could reconcile these apparently disparate observations.

\subsection{Possible Reconciliation of the Observed Differences Between Techniques}

\subsubsection{Scenario 1: The OH Modes in the INS Spectra are Hidden by the $\mathrm{C}-\mathrm{H}$ Stretch and Bending Modes}

The INS spectra seen in Fig. 1 show no OH-related peaks in either the deformation or the $\mathrm{OH}$ stretch region. However, the $\mathrm{CH}$ stretch peak is quite broad suggesting that the $\mathrm{OH}$ peak could be contributing to the total intensity. Hydrogen bonding not only broadens peaks but also shifts them. Strong hydrogen bonding shifts the deformation modes to higher wavenumber and the stretching modes to lower wavenumber [27]. It is conceivable that the $\mathrm{OH}$ deformation modes of methanol have upshifted under the $\mathrm{CH}_{3}$ rocking modes at $1100-1200 \mathrm{~cm}^{-1}$ and that the $\mathrm{OH}$ stretch modes have downshifted under the $\mathrm{CH}$ stretching modes. To investigate this possibility a deuterated methanol $\left(\mathrm{CD}_{3} \mathrm{OH}\right)$ was used to load the zeolite under exactly the same conditions as used for the spectra in Fig. 1 and the INS spectra measured. Figure 4 shows the solid $\mathrm{CD}_{3} \mathrm{OH}$ reference data obtained by both TOSCA and MAPS, as well as the spectra of the $\mathrm{CD}_{3} \mathrm{OH}$ dosed on ZSM-5, with the zeolite contribution subtracted (FD-CD3OH, $17.8 \mathrm{~mol}_{\mathrm{CD} 3 \mathrm{OH}} / \mathrm{mol}_{\mathrm{ZSM}-5,} \sim 6 \mathrm{CD}_{3} \mathrm{OH} /$ acid site). 

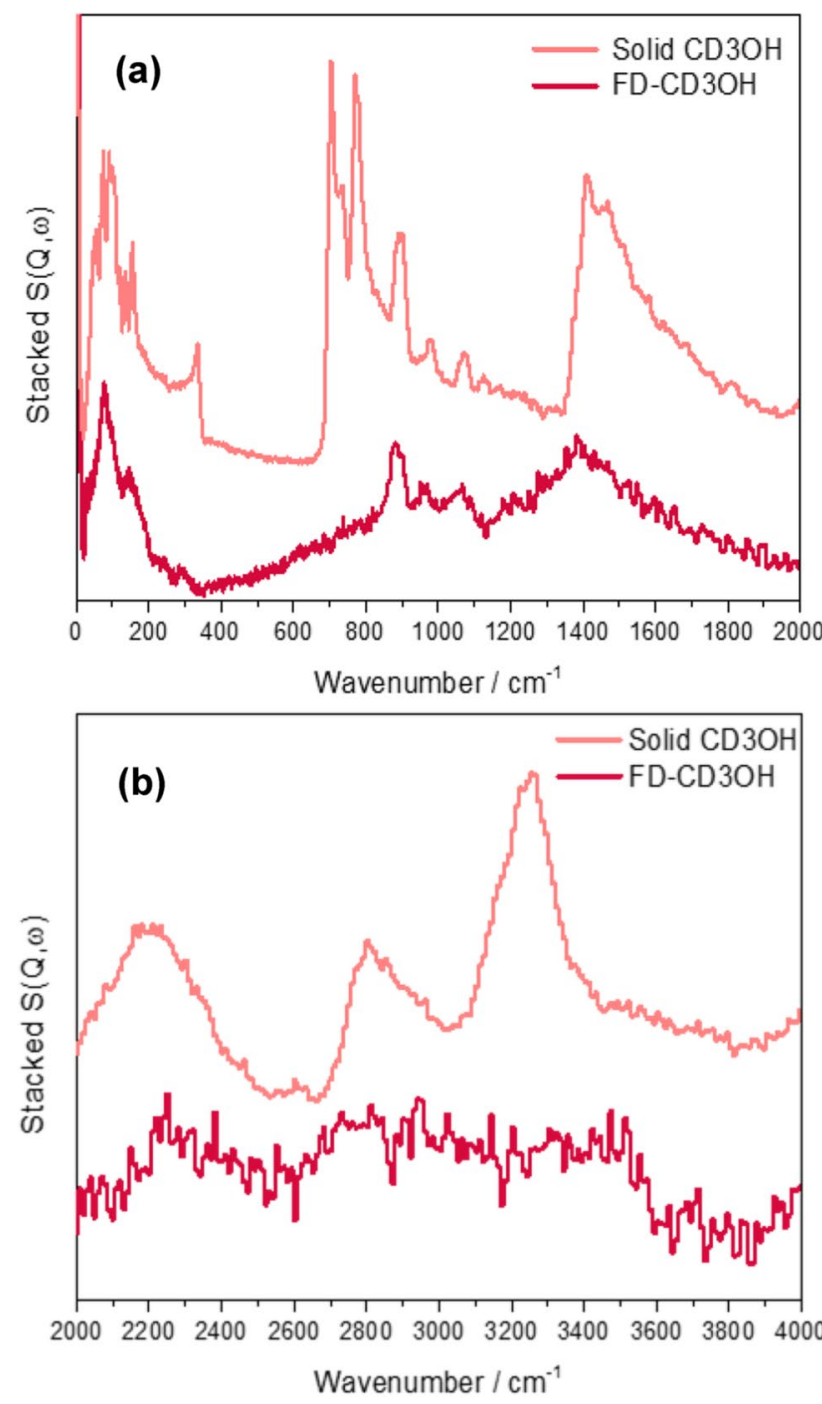

Fig. 4 INS spectra of solid $\mathrm{CD}_{3} \mathrm{OH}$ and $\mathrm{CD}_{3} \mathrm{OH}$ flow dosed on ZSM-5 at room temperature. a Spectra collected via TOSCA spectrometer b Spectra collected with MAPS spectrometer (A-chopper) with incident energy set at $5244 \mathrm{~cm}^{-1}$

From the TOSCA spectra spectra (Fig. 4a), it is seen that for the adsorbed molecule the $\mathrm{OH}$ deformation modes at 702 and $768 \mathrm{~cm}^{-1}$ are no longer present, whereas the $\mathrm{CD}_{3}$ rock at $895 \mathrm{~cm}^{-1}$ is still observed. There is a very broad peak $\left(\sim 800 \mathrm{~cm}^{-1}\right)$ underlying the methyl deformations, which could be the broadened $\mathrm{OH}$ deformation peaks. The peaks at 1405 and $1455 \mathrm{~cm}^{-1}$ in the reference spectrum are assigned to $\mathrm{OH}$ bending modes; it is unclear if the broad feature observed at $1390 \mathrm{~cm}^{-1}$ for the adsorbed molecule is due to the $\mathrm{OH}$ bending modes broadened. From the MAPS reference spectrum of $\mathrm{CD}_{3} \mathrm{OH}$ (Fig. 4b), three prominent peaks are seen: one at $2220 \mathrm{~cm}^{-1}$ that is assigned to the unresolved C-D stretch modes, one at $2800 \mathrm{~cm}^{-1}$ assigned to the overtone of the $\mathrm{OH}$ in-plane bending modes found at
$1405 \mathrm{~cm}^{-1}$ and, finally, the $3260 \mathrm{~cm}^{-1}$ feature assigned as the $\mathrm{OH}$ stretching mode [28].

From the MAPS spectrum of FD- $\mathrm{CD}_{3} \mathrm{OH}$ (Fig. 4b), the $\mathrm{C}$-D stretch modes are weak but distinguishable, whereas the two $\mathrm{OH}$ assigned modes are either absent or broadened to $>1000 \mathrm{~cm}^{-1}$ width. This $\mathrm{CD}_{3} \mathrm{OH}$ experiment is thus inconclusive, and does not give a clear answer as to the interaction of methanol with the zeolite at room temperature.

\subsubsection{Scenario 2: Both Hydrogen Bonded Species and Methoxy Species are Present}

It is difficult to distinguish the two species via infrared spectroscopy due to the different extinction coefficients of $\nu(\mathrm{O}-\mathrm{H})$ and $\nu(\mathrm{C}-\mathrm{H})$. The DRIFTS experiments of Matam et al., have suggested that at saturation levels of methanol, methoxylation is possible $[17,18]$. However, the spectra are dominated by the $\mathrm{ABC}$ triplet of hydrogen-bonded methanol. This potentially hides any methoxy peaks, as was seen in Fig. 3. To check this possibility, methanol was injected at room temperature, the zeolite heated to $523 \mathrm{~K}$ where methoxylation is expected to occur [8-10], cooled back to room temperature and the same amount of methanol injected again. Both the heating and injections occurred under a nitrogen flow of $10 \mathrm{ml} \mathrm{min}^{-1}$, with the total methanol injection each time being $12 \mu \mathrm{l}$. The spectra recorded are shown in Fig. 5.

The first room temperature spectrum is that of hydrogen bonded methanol, with the $\mathrm{ABC}$ triplet clearly dominating the spectra. The extinction coefficient of the $\mathrm{OH}$ stretching modes is clearly much larger than that of the $\mathrm{CH}$ stretching modes. A crude estimate of the total integrated area of the $\mathrm{CH}$ stretching modes compared with that of the $\mathrm{OH}$ stretching modes (ESI Figure S9) indicates a difference of at least 20-fold.

With progressive heating, the bands due to hydrogenbonded methanol diminish. In the $\mathrm{CH}$ stretching region (Fig. 5b) the bands observed match those reported in the literature for hydrogen bonded dimethylether [11, 26], at $3010,2971,2945$ and $2840 \mathrm{~cm}^{-1}$. The two bands expected for surface methoxy groups (asymmetric and symmetric stretching modes at 2980 and $2868 \mathrm{~cm}^{-1}$ respectively are not clearly seen, although their presence can be inferred from the formation of dimethylether. The low frequency difference spectra show the appearance of a new band at $870 \mathrm{~cm}^{-1}$ on heating to $523 \mathrm{~K}$. We suggest this band may be the symmetric $\mathrm{C}-\mathrm{O}-\mathrm{C}$ stretch of adsorbed dimethylether, down shifted from the gas-phase value of $928 \mathrm{~cm}^{-1}$ by hydrogen bonding [29]. On cooling to room temperature and reinjection of methanol, the spectrum obtained is almost indistinguishable from that obtained initially, showing loss of the $870 \mathrm{~cm}^{-1}$ band of dimethylether and appearance again of hydrogen bonded methanol. Any methoxy groups which 

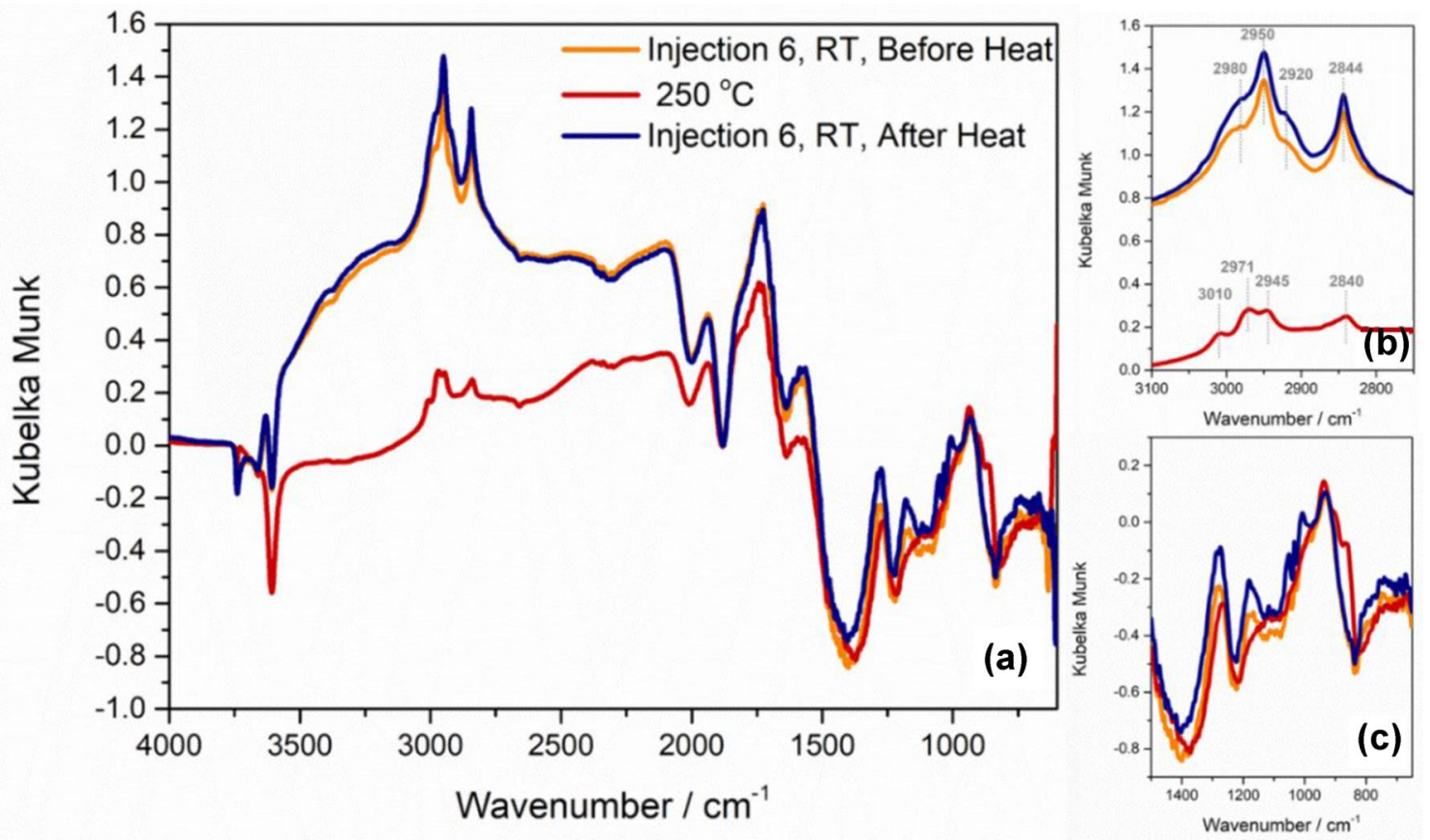

Fig. 5 a DRIFTS difference spectra, 6 injections of $2 \mu$ methanol at room temperature at $20 \mathrm{ml} / \mathrm{min}$ nitrogen flow, heated to $523 \mathrm{~K}$ at $5 \mathrm{~K} \mathrm{~min}^{-1}$, cooled to room temperature and 6 further injections, $2 \mu 1$

may have been formed at $523 \mathrm{~K}$ are completely obscured by the hydrogen bonded methanol.

\subsubsection{Scenario 3: The Difference Between INS and NMR is Due to the Dosing Differences}

Under the right conditions, both NMR and INS are quantitative techniques, which makes their discrepancies in this issue the more surprising. One difference between the techniques is the sample mass required: NMR having an approximate sample size of $0.5 \mathrm{~g}$ and INS usually needing up to $12 \mathrm{~g}$ of sample to obtain good S/N spectra with the TOSCA and MAPS instruments. Due to this disparity it could be argued that a sample size effect (during the dosing of the samples) is responsible for methoxylation occurring in the INS sample. Another possible explanation is that the INS samples have been prepared under flow conditions, whereas most NMR experiments have been performed with static dosing. Both of these possibilities are explored below.

Dosing effect The dosing effect was checked by preparing a static dosed ZSM-5 in large enough quantities for an INS measurement. In order to do that, the sample was dried and then kept in a desiccator containing a saturated vapour pressure of methanol for $70 \mathrm{~h}$ before being transferred into the spectrometer. Figure 6, shows the MAPS spectrum (SM$\mathrm{MEOH}, 15.5 \mathrm{~mol}_{\mathrm{MeOH}} / \mathrm{mol}_{\mathrm{ZSM} 5}$, approximately 5 methanol methanol. Difference spectra obtained by subtracting the spectrum of the dehydrated zeolite. b Detailed view of the $\mathrm{CH}$ region $(3300$ $2500 \mathrm{~cm}^{-1}$ ) c Detailed view of the $650-1500 \mathrm{~cm}^{-1}$ region

molecules per acid site) recorded with an incident energy of $5244 \mathrm{~cm}^{-1}$. The stretching region does not show any differences from previous INS experiments. In the deformation region, there is a broad weak feature where the $\mathrm{OH}$ deformation peaks should be. Figure $6 \mathrm{~b}$ shows the TOSCA spectrum of the same sample, which suggests that the broadness observed, is not due to the low resolution resulting from the use of $5243 \mathrm{~cm}^{-1}$ incident energy to observe the $\mathrm{C}-\mathrm{H}$ and $\mathrm{O}-\mathrm{H}$ stretch region. It is very broad, suggesting that the hydrogen bonding is very strong, but its intensity still does not match that expected for $15 \mathrm{~mol}$ of methanol per ZSM-5 unit cell.

It is also noteworthy that no water is observed in the INS spectrum at Fig. 6. Any water formed by methoxylation (Scheme 1) should remain in the zeolite in a static experiment and be observable. Water has very characteristic librational modes which occur at $400-800 \mathrm{~cm}^{-1}[30,31]$ as well as characteristic $\mathrm{HOH}$ deformation and stretching modes which do not appear to be present, although distinguishing these from the $\mathrm{OH}$ modes of hydrogen bonded methanol may be problematical. The broadness observed in the deformation region could possibly be due to water present at low concentrations, although the high (for water) transition energy of $600-800 \mathrm{~cm}^{-1}$ strongly militates against this assignment. It is not possible from this experiment to know if it is due to a small quantity of methanol converting to methoxy or due to the dosing procedure. We note that there 

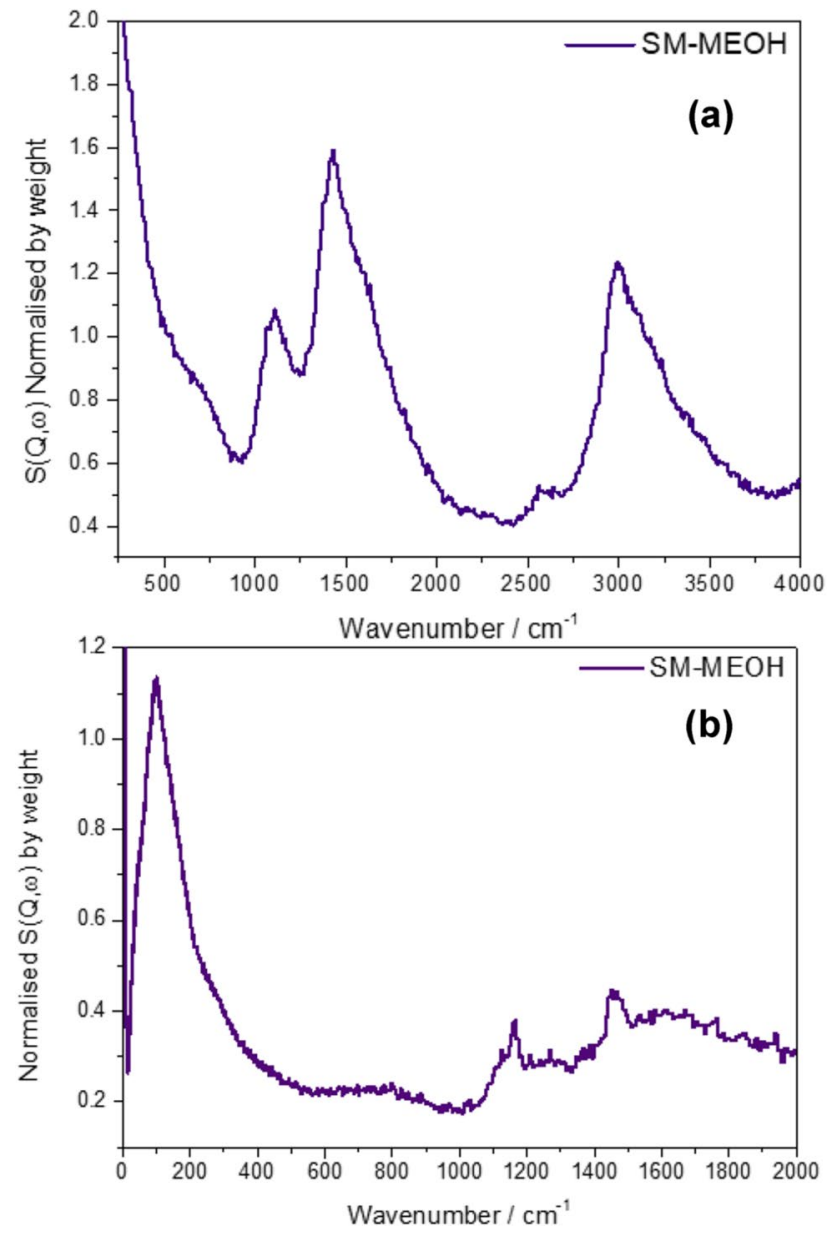

Fig. 6 a INS spectrum of static dosed methanol on ZSM-5. The spectrum was normalised using the sample weight. The spectrum was recorded with the MAPS spectrometer, using the A-chopper package at an incident energy of $5243 \mathrm{~cm}^{-1}$. b INS spectrum of static dosed methanol using the TOSCA spectrometer.

are no other peaks present that could be assigned to water (translational modes, $\mathrm{H}-\mathrm{O}-\mathrm{H}$ bend and stretch).

We therefore designed a different experiment in which a flow-dosed sample was produced from a $14 \mathrm{wt} \%{ }^{13} \mathrm{C}$ methanol in ${ }^{12} \mathrm{C}$-methanol mixture in sufficient quantity to be analysed firstly by INS and then with ${ }^{13} \mathrm{C}$ NMR and DRIFTS. The total methanol loading is $17.8 \mathrm{moles}_{\mathrm{MeOH}} / \mathrm{moles}_{\mathrm{ZSM}-5}$ (approximately 6 methanols per acid site). The spectra obtained from this sample with the three different techniques are presented in Fig. 7. This experiment eliminates the possibility of different dosing conditions giving different results. The ss-NMR spectrum shows that there are no methoxy groups or dimethylether present in the ${ }^{13} \mathrm{C}$-methanol loaded zeolite sample, as there are no signals at $60 \mathrm{ppm}$. The DRIFTS spectrum is dominated by the bands due to hydrogen bonded methanol, as discussed above, and no bands due to methoxy groups can be distinguished. The INS spectrum shows similar features to those described above, with the possibility at least of weak broad shoulders in the $\mathrm{OH}$ deformation and $\mathrm{OH}$ stretching regions which could indicate the presence of hydroxyl groups.

\subsubsection{Scenario 4: OH Peaks Present at INS Spectra are Broadened to the Point of No Detection}

This hypothesis assumes that the hydrogen bonding is so strong that it causes the $\mathrm{OH}$ peaks to broaden out to the point that they become part of the baseline and are undetectable by INS spectroscopy. Hydrogen and deuterium have different neutron cross- sections and this allows us to test this possibility. A ZSM-5 sample was first loaded with $\mathrm{CH}_{3} \mathrm{OD}$ and the spectrum measured with the MAPS spectrometer. The same zeolite sample was then exposed to $\mathrm{CH}_{3} \mathrm{OH}$ to the same concentration and re-measured. If methoxylation had occurred, then there should be no difference between the spectra of the $\mathrm{CH}_{3} \mathrm{OD}$ and $\mathrm{CH}_{3} \mathrm{OH}$ exposed samples because the methoxy group has no deuterium incorporation. If methanol is present as a hydrogen-bonded species but with extremely broad $\mathrm{OH}$-related bands, then the exchange of $\mathrm{CH}_{3} \mathrm{OD}$ for $\mathrm{CH}_{3} \mathrm{OH}$ should result in a raised baseline because of the larger total cross section of ${ }^{1} \mathrm{H}$ (82.03 barn) versus ${ }^{2} \mathrm{H}$ (7.64 barn) [32]. Figure 8 shows the results of this experiment. (Extended range spectra are shown in Figure $\mathrm{S} 10)$. The sample was exposed to $\mathrm{CH}_{3} \mathrm{OD}$ first to a loading of $15.3 \mathrm{~mol}_{\mathrm{CH} 3 \mathrm{OD}} / \mathrm{mol}_{\mathrm{ZSM}-5}$, and then the same sample was exposed to a flow saturated with normal methanol $\left(\mathrm{CH}_{3} \mathrm{OH}\right)$. The sample mass increased to a loading of $15.7 \mathrm{~mol}_{\mathrm{CH} 3 \mathrm{OH}} /$ mol $_{\text {ZSM- }-5}$.

It can be seen that the spectra do not overlap and that the $\mathrm{CH}_{3} \mathrm{OH}$ dosed spectra have gained intensity. This demonstrates that the methanol did not undergo methoxylation and that the methanol is present as a hydrogen-bonded species, albeit with extremely broad OH-related modes. This interpretation is also supported by the transition energies of the $\mathrm{CH}_{3}$ rocking modes [28]. Figure 8c compares the spectra of the pure $\mathrm{CH}_{3} \mathrm{OD}$ and $\mathrm{CH}_{3} \mathrm{OH}$ in the rocking mode region and it can be seen that the peaks occur at slightly different transition energies for the two isotopomers. For $\mathrm{CH}_{3} \mathrm{OH}$ they occur at 1120 and $1157 \mathrm{~cm}^{-1}$, whereas, for $\mathrm{CH}_{3} \mathrm{OD}$ they occur at 1167 and $1232 \mathrm{~cm}^{-1}$. Crucially, comparison with the spectra in Fig. 8a shows that this is also true of the $\mathrm{CH}_{3} \mathrm{OD}$ and $\mathrm{CH}_{3} \mathrm{OH}$ zeolite loaded spectra. This can only be the case if the $\mathrm{CH}_{3} \mathrm{OD}$ and $\mathrm{CH}_{3} \mathrm{OH}$ are intact in the zeolite.

\section{Conclusions}

This paper has shown that observing the $\mathrm{OH}$ functionality of methanol when methanol is loaded on ZSM-5 is complex with INS spectroscopy. When methanol is loaded on ZSM-5 

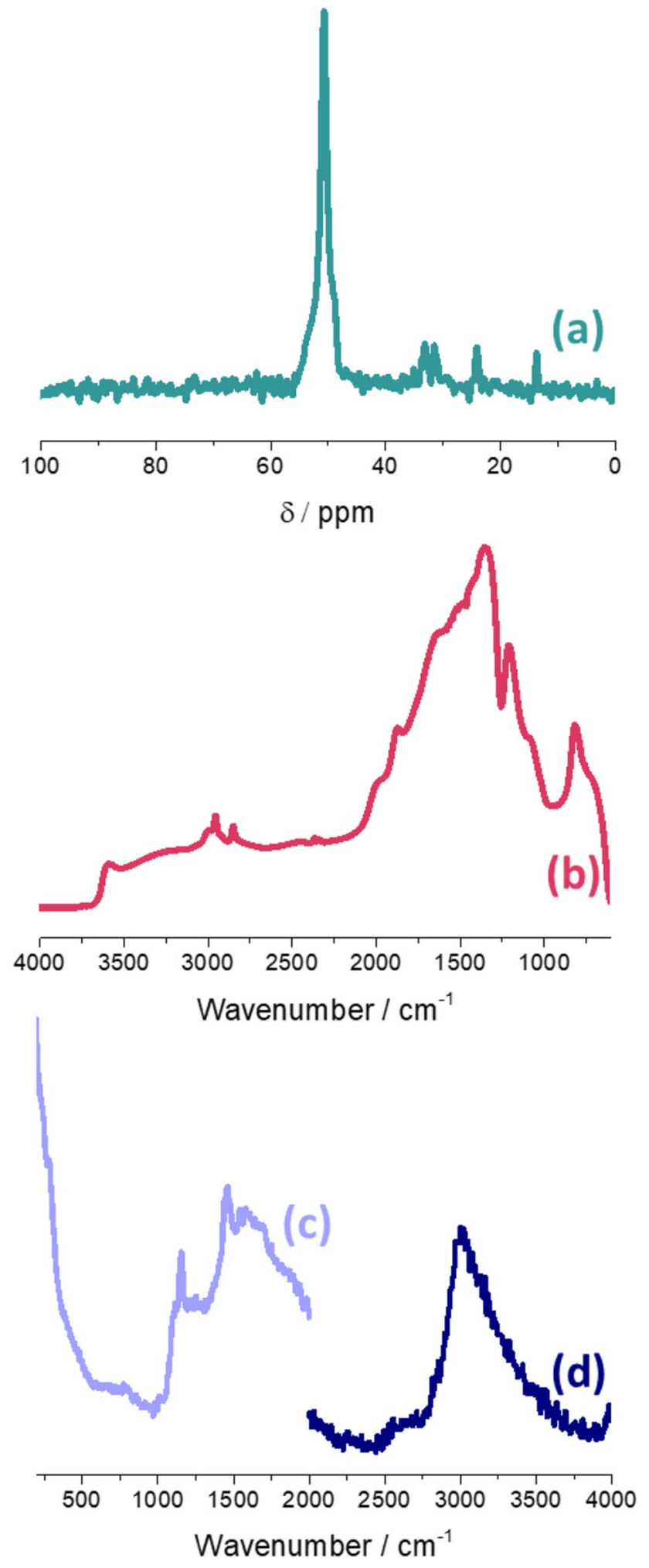

Fig. $7{ }^{13} \mathrm{C}$-Methanol dosed ZSM-5 sample spectra. a ${ }^{13} \mathrm{C}$-NMR spectrum b DRIFTS spectrum $\mathbf{c}$ INS spectrum collected with the TOSCA spectrometer d INS spectrum collected with the MAPS spectrometer using the A-chopper package at an incident energy of $5244 \mathrm{~cm}^{-1}$ at room temperature, both infrared and ss-NMR spectroscopies definitively show that the methanol $\mathrm{OH}$ functionality is still present and dominates both sets of spectra. With INS spectroscopy, the $\mathrm{OH}$ functionality is not immediately evident, which led to the previous conclusion that methanol is dissociated at room temperature. A small degree of methoxylation was suggested by infrared spectroscopy $[17,18]$ that could be attributed to differences in the experimental conditions employed. Theory suggests that methanol dissociation may be facilitated at higher loading and higher acid site density [18, 33]. However, our combined INS, DRIFTS and NMR studies on the same zeolite sample (Fig. 7) show at room temperature this occurs to a very limited extent. A variety of scenarios have been considered that could reconcile the apparent contradictions between the techniques. The explanation that best fits the observations is that methanol is largely ( $\geq 99 \%$ ) present as the hydrogen-bonded species at ambient temperature. This is consistent with the DRIFTS (Fig. 5) and ss-NMR (Fig. 3) data. This is also consistent with the $\mathrm{CD}_{3} \mathrm{OH}$ experiment (Fig. 4), which was previously thought to be inconclusive due to the lack of an $\mathrm{OH}$ peak present within the spectrum. Concerning the INS spectra (Fig. 1), the $\mathrm{OH}$-related modes have broadened to such an extent that they merge into the baseline so they are no longer clearly visible. This model also accounts for why there is no evidence of water in any of the INS spectra (Figs. 1, 4, $6,7)$. It was originally assumed that if methoxylation had occurred, then the water generated would be flushed out of the zeolite. While this is conceivable for the flow dosed system, the water by-product should have still been present in the static dosed samples, which it was not (Fig. 6). It is possible that the water stretch and bend modes could be masked by methoxy modes, however, the very strong librational modes would occur at $400-800 \mathrm{~cm}^{-1}$, which is a region that is clear of interference.

The presence of very broad $\mathrm{OH}$-related modes has some precedent in a study of $\mathrm{KH}_{2} \mathrm{AsO}_{4}$ [34] which is strongly hydrogen-bonded in the solid state. In this case, the $\mathrm{O}-\mathrm{H}$ stretch mode extends over a range of $\sim 2000 \mathrm{~cm}^{-1}$, although both the in-plane and out-of-plane As-O-H bending modes give distinct modes. For the adsorption system under consideration here, all of the methanol $\mathrm{OH}$-related modes are broadened to at least $1000 \mathrm{~cm}^{-1}$, which makes them very difficult to identify. The authors believe this to be a previously unrecognised phenomenon for this adsorption system, which warrants further study. 
Fig. 8 MAPS spectra of $\mathrm{CH}_{3} \mathrm{OD}$ dosed ZSM-5 vs exchanged $\mathrm{CH}_{3} \mathrm{OH}$ dosed ZSM5. Both spectra were collected using the A-chopper package at an incident energy of a $2016.75 \mathrm{~cm}^{-1}$ b $5243.55 \mathrm{~cm}^{-1}$. c Detailed view at the 1000 $1600 \mathrm{~cm}^{-1}$ of the pure $\mathrm{CH}_{3} \mathrm{OD}$ and $\mathrm{CH}_{3} \mathrm{OH}$ spectra collected via the TOSCA spectrometer for comparison purposes
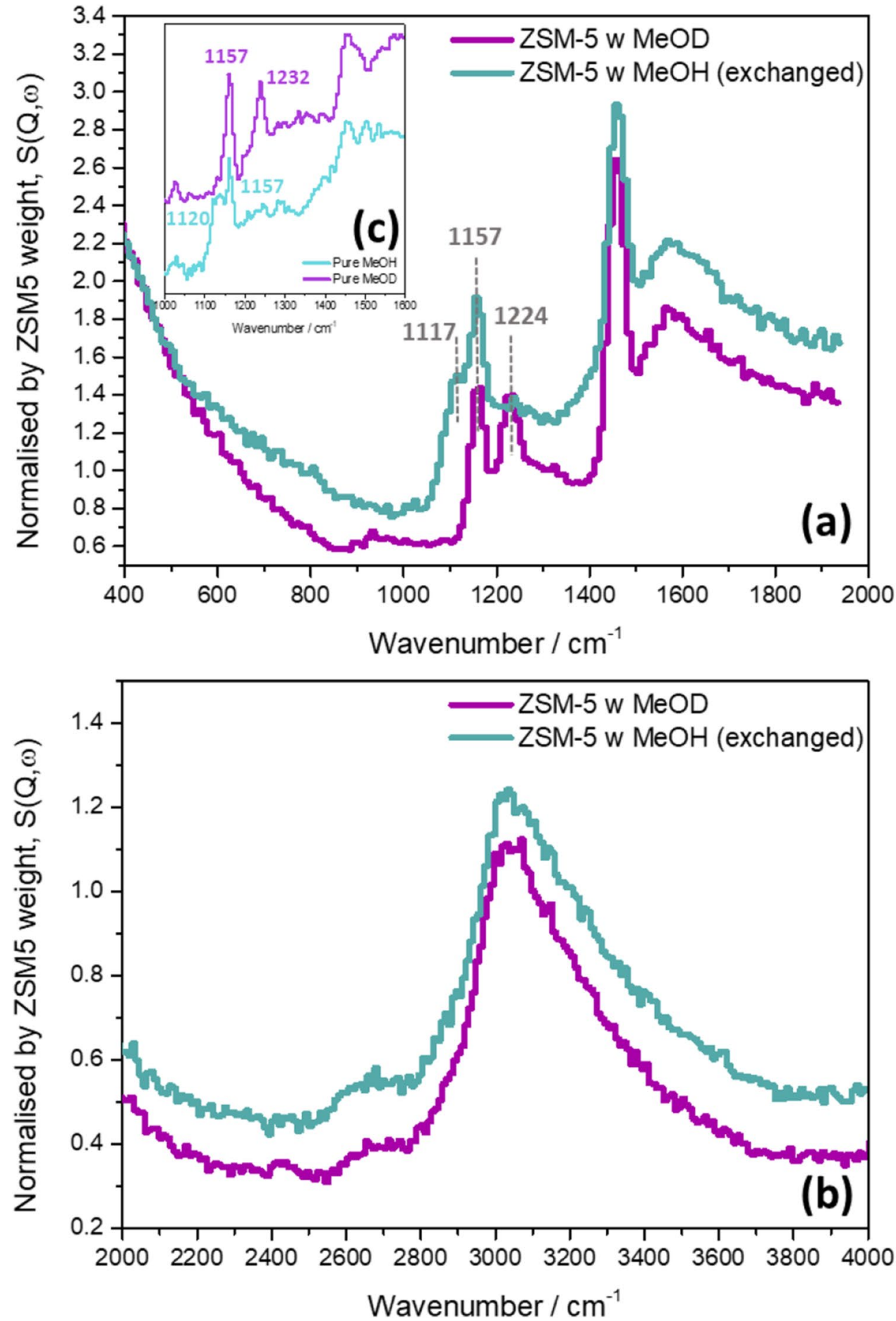

Supplementary Information The online version contains supplementary material available at https://doi.org/10.1007/s11244-021-01462-9.

Acknowledgements Johnson Matthey plc. is thanked for supplying the ZSM-5 zeolite and for financial support through the provision of industrial CASE studentships in partnership with the EPSRC (APH (EP/P510506/1, AZ (EP/N509176/1)). Experiments at the ISIS Neutron and Muon Source were made possible by beam time allocations from the Science and Technologies Facilities Council [35-38]. The resources and support provided by the UK Catalysis Hub via membership of the UK Catalysis Hub consortium and funded by EPSRC grants EP/R026815/1 and EP/R026939/1 are gratefully acknowledged. This research has been performed with the use of facilities and equipment at the Research Complex at Harwell; the authors are grateful to the Research Complex for this access and support.

Author Contributions AZ (Data acquisition and analysis, first draft and editing of manuscript). APH (Neutron data acquisition). RFH 
(Validation and manuscript editing). PC (Industrial supervision and project conceptualisation). NB (NMR spectroscopy). JB (NMR spectroscopy). DL (Project management, supervision, validation and manuscript editing). SFP (Project management, supervision, validation and manuscript editing).

Funding EPSRC, Johnson Matthey (through iCase studentships).

\section{Declarations}

Conflict of interest All the authors declared that they have no conflict of interest to disclose.

Open Access This article is licensed under a Creative Commons Attribution 4.0 International License, which permits use, sharing, adaptation, distribution and reproduction in any medium or format, as long as you give appropriate credit to the original author(s) and the source, provide a link to the Creative Commons licence, and indicate if changes were made. The images or other third party material in this article are included in the article's Creative Commons licence, unless indicated otherwise in a credit line to the material. If material is not included in the article's Creative Commons licence and your intended use is not permitted by statutory regulation or exceeds the permitted use, you will need to obtain permission directly from the copyright holder. To view a copy of this licence, visit http://creativecommons.org/licenses/by/4.0/.

\section{References}

1. Chang CD, Silvestri AJ (1977) The conversion of methanol and other O-compounds to hydrocarbons over zeolite catalysts. J Catal 47:249-259

2. Chang CD (1983) Hydrocarbons from methanol. Catal Rev 25:1-118

3. Haw JF, Song W, Marcus DM et al (2003) The mechanism of methanol to hydrocarbon catalysis. Acc Chem Res 36:317-326

4. Olsbye U, Svelle S, Lillerud KP et al (2015) The formation and degradation of active species during methanol conversion over protonated zeotype catalysts. Chem Soc Rev 44:7155-7176

5. Schulz H (2018) "Coking" of zeolites during methanol conversion: basic reactions of the MTO-, MTP- and MTG processes. Catal Lett 148:1263-1280

6. Yarulina I, Chowdhury A, Meirer F et al (2018) Recent trends and fundamental insights in the methanol-to-hydrocarbons process. Nat Catal 1:398-411

7. Wang C, Xu J, Deng F (2020) Mechanism of methanol-to-hydrocarbon reaction over zeolites: a solid-state NMR perspective. ChemCatChem 12:965-980

8. Ono Y, Mori T (1981) Mechanism of methanol conversion into hydrocarbons over ZSM-5 zeolite. J Chem Soc Faraday Trans I 77:2209-2221

9. Wang W, Hunger M (2008) Reactivity of surface alkoxy species on acidic zeolite catalysts. Acc Chem Res 41:895-904

10. Forester TR, Howe RF (1987) In situ FTIR studies of methanol and dimethyl ether in ZSM-5. J Am Chem Soc 109:5076-5082

11. Zecchina A, Bordiga S, Spoto G et al (1996) IR spectroscopy of neutral and ionic hydrogen-bonded complexes formed upon interaction of $\mathrm{CH}_{3} \mathrm{OH}, \mathrm{C}_{2} \mathrm{H}_{5} \mathrm{OH},\left(\mathrm{CH}_{3}\right)_{2} \mathrm{O},\left(\mathrm{C}_{2} \mathrm{H}_{5}\right)_{2} \mathrm{O}$ and $\mathrm{C}_{4} \mathrm{H}_{8} \mathrm{O}$ with H-Y, H-ZSM-5 and H-mordenite: comparison with analogous adducts formed on the H-Nafion superacidic membrane. $\mathrm{J}$ Chem Soc Faraday Trans 92:463-4875
12. Claydon MF, Sheppard N (1969) The nature of “A, B, C"-type infrared spectra of strongly hydrogen-bonded systems; Pseudomaxima in vibrational spectra. J Chem Soc D Chem Comm 23:1431-1433

13. Palmenschikov AG, van Santen RA, Jänchen J et al (1993) $\mathrm{CD}_{3} \mathrm{CN}$ as a probe of Lewis and Brønsted acidity of zeolites. $\mathrm{J}$ Phys Chem 97:11071-11074

14. O'Malley AJ, Parker SF, Chutia A et al (2016) Room temperature methoxylation in zeolites: insight into a key step of the methanol to hydrocarbons process. Chem Commun 52:2897-2900

15. Matam SK, O'Malley AJ, Catlow CRA et al (2018) The effects of MTG catalysis on methanol mobility in ZSM-5. Catal Sci Technol 8:3304-3312

16. Omojola T, Silverwood IP, O’Malley AJ (2020) Molecular behaviour of methanol and dimethyl ether in H-ZSM-5 catalysts as a function of $\mathrm{Si} / \mathrm{Al}$ ratio: a quasielastic neutron scattering study. Catal Sci Technol 10:4305-4320

17. Matam SK, Howe RF, Thetford A et al (2018) Room temperature methoxylation in zeolite H-ZSM-5: an operando DRIFTS/ mass spectrometric study. Chem Commun 54:12875-12878

18. Matam SK, Nastase SAF, Logsdail AJ et al (2020) Methanol loading dependent methoxylation in zeolite H-ZSM-5. Chem Sci 11:6805-6814

19. Suwardiyanto S, Howe RF, Gibson EK et al (2017) An assessment of hydrocarbon species in the methanol-to-hydrocarbon reaction over a ZSM-5 catalyst. Faraday Discuss 197:447-472

20. Pinna RS, Rudić S, Parker SF et al (2018) The neutron guide upgrade of the TOSCA spectrometer. Nucl Instrum Methods Phys Res B 896:68-74

21. Parker SF, Lennon D, Albers PW (2011) Vibrational spectroscopy with neutrons: a review of new directions. Appl Spectrosc 65:1325-1341

22. Zachariou A, Hawkins AP, Lennon D et al (2019) Investigation of ZSM-5 catalysts for dimethylether conversion using inelastic neutron scattering. Appl Catal A Gen 569:1-7

23. Zachariou A, Hawkins AP, Collier P et al (2020) The effect of co-feeding methyl acetate on the H-ZSM5 catalysed methanolto-hydrocarbons reaction. Top Catal 63:370-377

24. Torrie BH, Weng SX, Powell BM (1989) Structure of the $\alpha$-phase of solid methanol. Mol Phys 67:575-581

25. Bordiga S, Regli L, Lamberti $\mathrm{C}$ et al (2005) FTIR adsorption studies of $\mathrm{H}_{2} \mathrm{O}$ and $\mathrm{CH}_{3} \mathrm{OH}$ in the isostructural H-SSZ-13 and $\mathrm{H}$-SAPO-34: formation of $\mathrm{H}$-bonded adducts and protonated clusters. J Phys Chem B 109:7724-7732

26. Campbell SM, Jiang XZ, Howe RF (1999) Methanol to hydrocarbons: spectroscopic studies and the significance of extraframework aluminium. Microporous Mesoporous Mater 29:91-108

27. Jeffrey GA (1997) An introduction to hydrogen bonding. Oxford University Press, Oxford

28. Falk M, Whalley E (1961) Infrared spectra of methanol and deuterated methanols in gas, liquid, and solid phases. J Chem Phys 34:1554-1568

29. Allan A, McKean DC, Perchard JP et al (1971) Vibrational spectra of crystalline dimethyl ethers. Spectrochim Acta A Mol Spectrosc 27A:1409-1437

30. Corsaro C, Crupi V, Majolino D et al (2006) Inelastic neutron scattering study of water in hydrated LTA-type zeolites. J Phys Chem A 110:1190-1195

31. Li J (1996) Inelastic neutron scattering studies of hydrogen bonding in ices. J Chem Phys 105:6733-6755

32. Sears VF (1992) Neutron scattering lengths and cross sections. Neutron News 3:26-37 
33. Nastase SAF, Cnudde P, Vanduyfhuys L et al (2020) Computational QM/MM investigation of the adsorption of MTH active species in H-Y and H-ZSM-5. ACS Catal 10:8904-8915

34. Tomkinson J, Parker SF, Lennon D (2010) No evidence for Evans' holes in the A, B, C vibrational structure of potassium dihydrogen arsenate. J Chem Phys 133:034508

35. Lennon D, Zachariou A, Hawkins AP, Collier P, Parker SF (2018) STFC, ISIS Neutron Muon Source. https://doi.org/10. 5286/ISIS.E.RB1810859

36. Lennon D, Collier P, Zachariou A, Hawkins AP, Collier P, Parker SF (2019) STFC, ISIS Neutron Muon Source. https:// doi.org/10.5286/ISIS.E.RB1910561
37. Lennon D, Zachariou A, Howe RF, Hitchcock I, Hawkins A, Parker SF (2019) STFC, ISIS Neutron Muon Source. https:// doi.org/10.5286/ISIS.E.RB1920589

38. Lennon D, Hawkins A, Zachariou A, Collier P, Parker SF, Howe RF (2018) STFC, ISIS Neutron Muon Source. https://doi.org/10. 5286/ISIS.E.RB1820116

Publisher's Note Springer Nature remains neutral with regard to jurisdictional claims in published maps and institutional affiliations. 